\title{
Penanganan Post Traumatic Stress Disorder (PTSD) pada Korban Bencana Lumpur Sidoarjo dengan Pendekatan Arsitektur Perilaku
}

\author{
Satriani Dian Pertiwi dan Nur Endah Nuffida \\ Departemen Arsitektur, Fakultas Teknik Sipil dan Perencanaan, Institut Teknologi Sepuluh Nopember (ITS) \\ e-mail: may_d@arch.its.ac.id
}

\begin{abstract}
Abstrak-Dampak yang ditimbulkan akibat bencana alam sangat kompleks, salah satunya yaitu mengenai dampak psikis. Dampak psikis yang sering ditemui pada masyarakat korban bencana alam adalah Stres Pascatrauma atau Post Traumatic Stress Disorder (PTSD). Pada jurnal ini menjelaskan bagaimana solusi untuk mengatasi masalah pada daerah terdampak bencana alam terutama menekankan pada masalah psikis melalui pengaplikasian desain-desain arsitektur. Psikis atau psikologi erat kaitannya dengan perilaku, sehingga pendekatan desain yang diangkat dalam jurnal ini adalah pendekatan arsitektur perilaku. Pendekatan arsitektur perilaku yakni menekankan pada hubungan dialektik antara ruang dengan manusia atau masyarakat yang memanfaatkan atau yang menghuni ruang tersebut. Pendekatan ini menekankan pada perlunya memahami perilaku dan kebutuhan masyarakat yang menghuni di suatu daerah tertentu dalam memanfaatkan ruang. Sedangkan konsep yang diangkat adalah konsep Healing Environment, yaitu lingkungan fisik suatu desain arsitektur yang dapat mempercepat pemulihan pengguna atau pasien secara psikis. Dengan pendekatan dan konsep ini diharapkan mampu mengatasi dampak psikis yang dialami oleh para korban bencana alam.
\end{abstract}

Kata Kunci-Arsitektur Perilaku, Bencana Alam, Lingkungan Pemulihan, Pemulihan Stress, Pusat Kesehatan Mental, Stres Pascatrauma.

\section{PENDAHULUAN}

SALAH satu masalah yang dihadapi oleh setiap individu $S_{\text {adalah masalah stres. Stres merupakan sebuah respon yang }}$ dialami setiap individu yang membebani atau membahayakan kehidupan penderita, yang meliputi fisik, psikologis, sosial dan lain sebagainya.

Salah satu dampak psikologis yang sering ditemui pada masyarakat korban bencana alam adalah Post Traumatic Stress Disorder (PTSD) atau sering disebut dengan stres pascatrauma. PTSD adalah suatu sindrom yang dialami oleh seseorang yang mengalami kejadian yang traumatis dan individu tersebut tidak mampu menghilangkan ingatan akan kejadian traumatis tersebut dari pikirannya.

Konteks yang diangkat adalah konteks pemulihan psikis (healing), yaitu upaya untuk memulihkan mental dan psikis para korban bencana.

Dalam menentukan solusi desain arsitektur yaitu dengan mengklasifikasikan terlebih dahulu dampak-dampak yang ditimbulkan dari suatu bencana. Lalu dari dampak-dampak tersebut dapat diperoleh beberapa solusi. Solusi tersebut berupa Pusat Terapi Mental / Pusat Pemulihan Psikis yang terintegrasi dengan tempat tinggal sementara untuk korban bencana, pusat komunitas untuk pemulihan psikis berupa taman pemulihan (healing park), dan Balai Latihan Kerja (BLK).

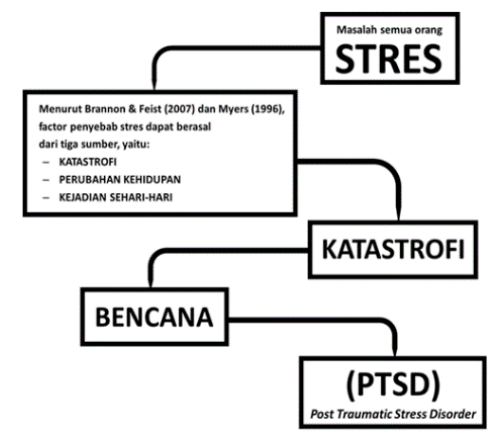

Gambar 1. Skema Latar Belakang

Sumber: Dokumentasi Pribadi

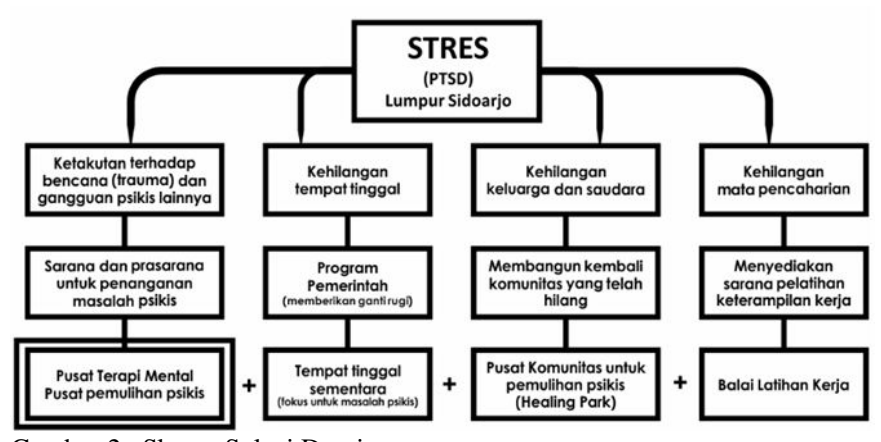

Gambar 2 . Skema Solusi Desain

Sumber: Dokumentasi Pribadi

\section{PIENDEKATAN DESAIN}

Desain pada Pusat Kesehatan Mental ini menggunakan pendekatan perilaku (behavior) yakni menekankan pada hubungan dialektik antara ruang dengan manusia atau masyarakat yang memanfaatkan atau yang menghuni ruang tersebut. Pendekatan ini menekankan pada perlunya memahami perilaku dan kebutuhan masyarakat yang menghuni di suatu daerah tertentu dalam memanfaatkan ruang [1].

Karena fokusan dari desain ini adalah mengatasi masalah psikis atau psikologi dari korban bencana alam maka pendekatan yang sesuai adalah pendekatan perilaku (behavior) atau dalam istilah arsitektur disebut pula arsitektur perilaku (behavior architecture). First we shape our buildings, then they shape us, then we shape them again-ad infinitum (toinfinity) [2]. 

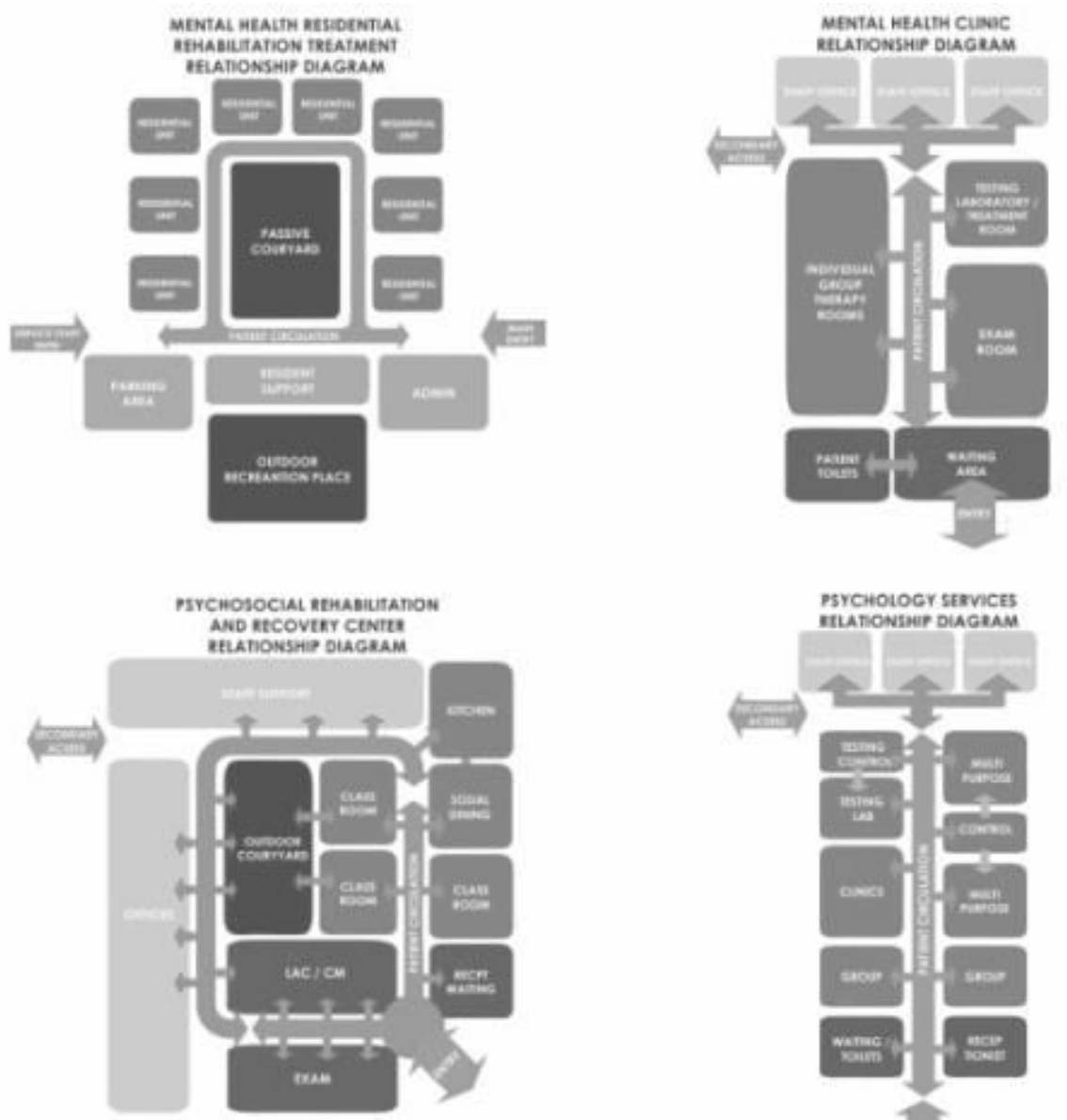

Gambar 3. Program Ruang.

Sumber: Robert L Neary, Jr [3] \& Dokumentasi Pribadi.

\section{PENDEKATAN DESAIN}

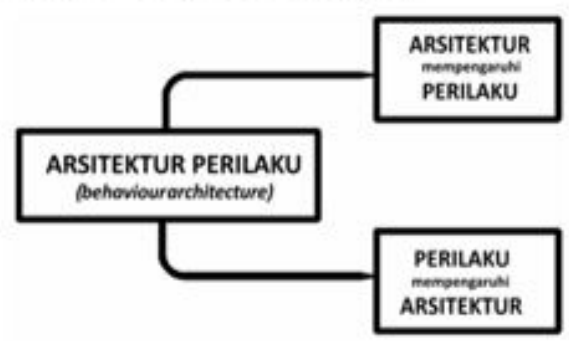

Gambar 4 . Skema Pendekatan Desain

Sumber: Dokumentasi Pribadi

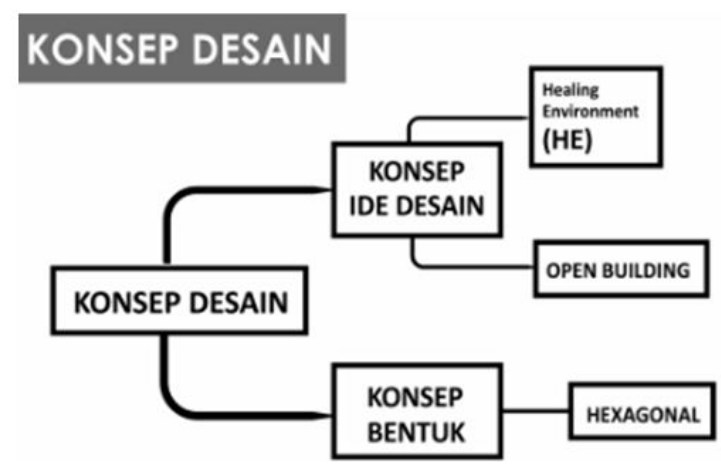

Gambar 5 . Konsep Desain

Sumber: Dokumentasi Pribadi
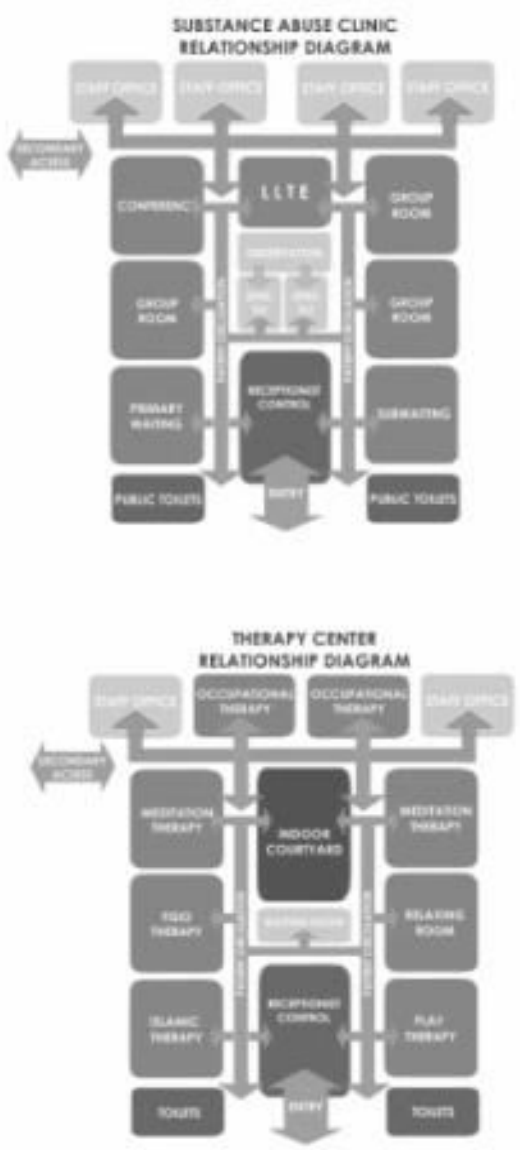

Gambar 6. Tapak lahan dan Bangunan Sekita Sumber: Dokumentasi Pribadi.

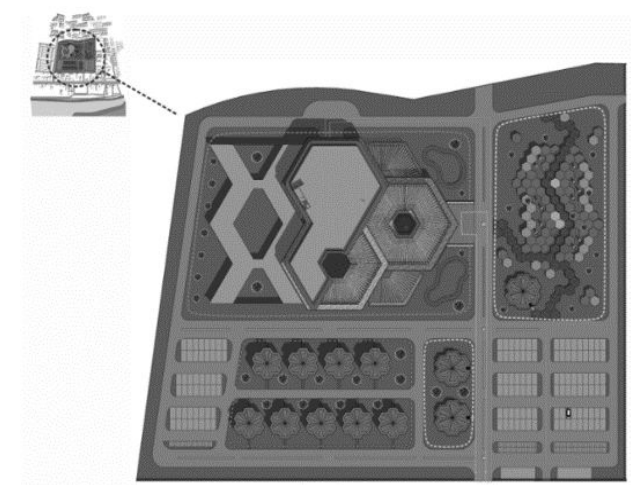

Gambar 7. Sitelplan dan Perbesaran Lahan

Sumber: Dokumentasi Pribadi 


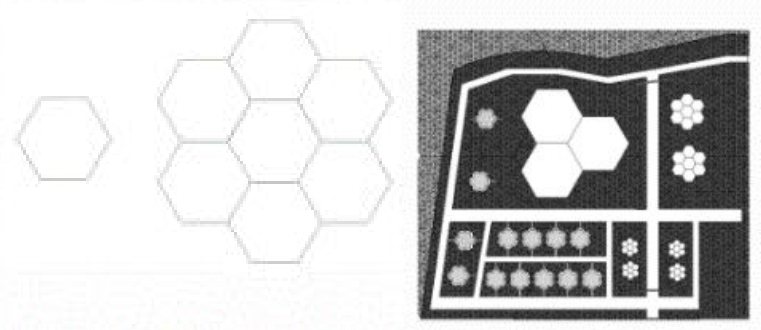

Gambar 8. Bentuk Heksagonal

Sumber: Dokumentasi Pribadi

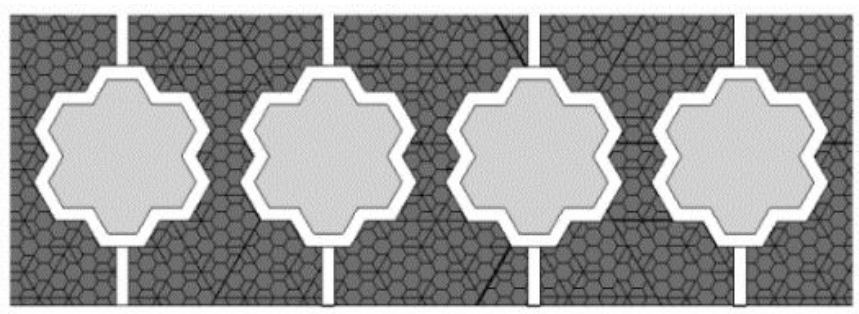

Gambar 9. Sistem Grid Heksagonal

Sumber: Dokumentasi Pribadi

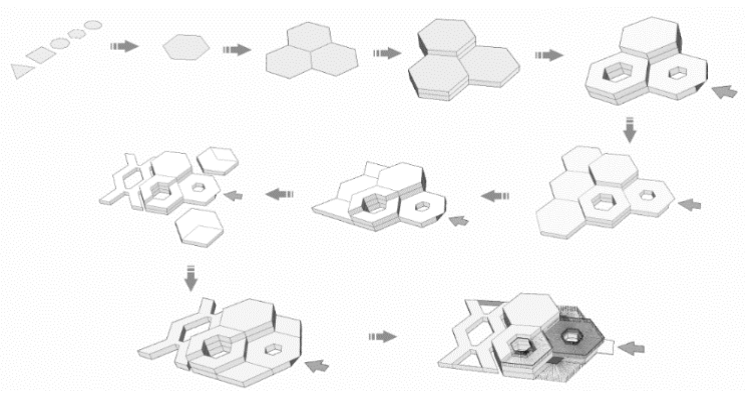

Gambar 10. Transformasi Bentuk Heksagonal

Sumber: Dokumentasi Pribadi

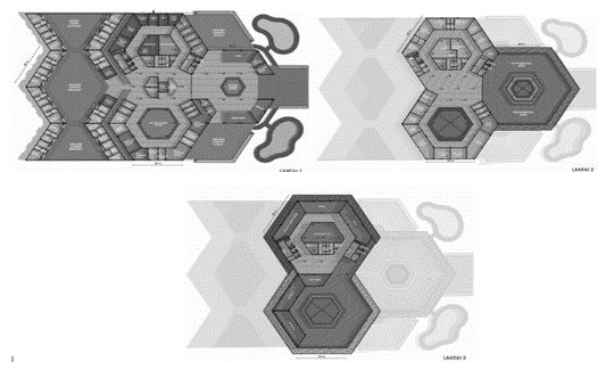

Gambar 11. Denah Lantai 1,2,3

Sumber: Dokumentasi Pribadi

Arsitektur perilaku dibagi menjadi dua yaitu:

1. Arsitektur Mempengaruhi Perilaku (we shape our buildings)

Diharapkan dengan adanya fasilitas-fasilitas ini pada area terdampak bencana dapat mengatasi masalah psikis korban bencana lumpur Sidoarjo terutama masalah stres pascatrauma.

2. Perilaku Mempengaruhi Arsitektur (buildings shape us)

Desain yang dibuat berdasarkan pada aktivitas-aktivitas dan kebiasaan masyarakat sekitar bencana lumpur Sidoarjo baik dari segi social, budaya, dan ekonomi.
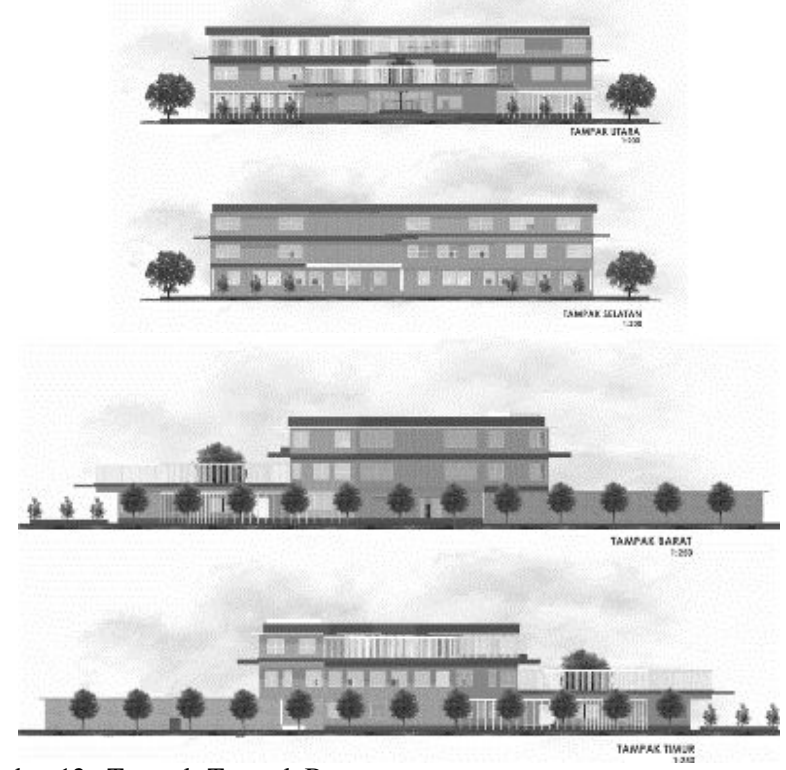

Gambar 12 . Tampak-Tampak Bangunan Sumber: Dokumentasi Pribadi

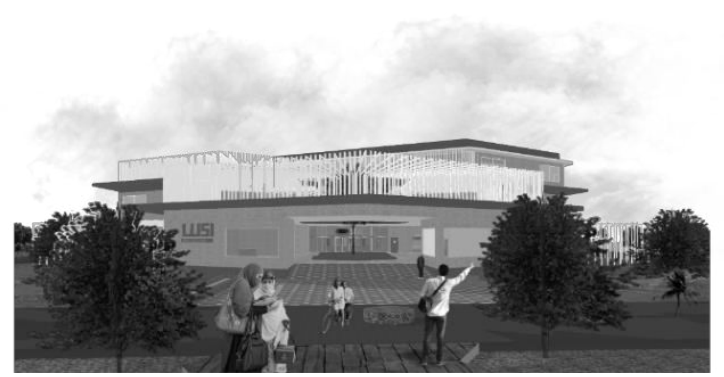

Gambar 13. Suasana Gedung Utama LUSI Mental Sumber: Dokumentasi Pribadi

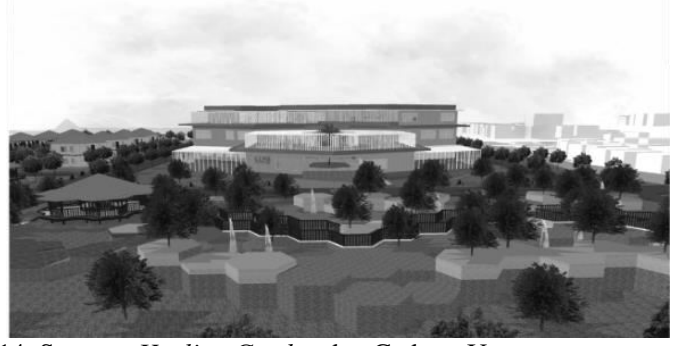

Gambar 14. Suasana Healing Garden dan Gedung Utama Sumber: Dokumentasi Pribadi.

\section{KONSEP DESAIN}

\section{A. Konsep Healing Environment (HE)}

Prinsip user-centered design dalam konsep Healing Environment, tidak hanya diterapkan pada desain bagian luar (tata ruang luar) tetapi juga bagian dalam (tata ruang dalam) bangunan. Inti dari konsep ini adalah membangun suasana melalui penyesuaian semua elemen desain untuk dapat memberikan rangsangan positif bagi kelima panca indera manusia [4]. Sehingga konsep healing environment pada lingkungan fisik fasilitas kesehatan dapat mempercepat waktu pemulihan kesehatan pasien atau mempercepat proses adaptasi pasien dengan menekankan pada efek psikologis pasien di dalamnya. 


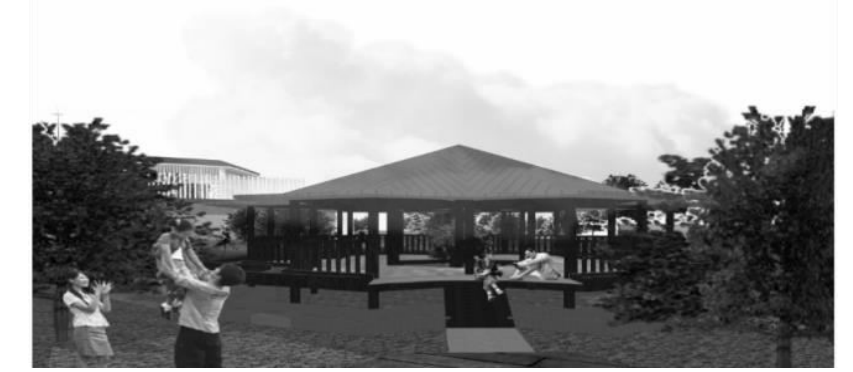

Gambar 15. Suasana Gazebo pada Healing Garden Sumber: Dokumentasi Pribadi

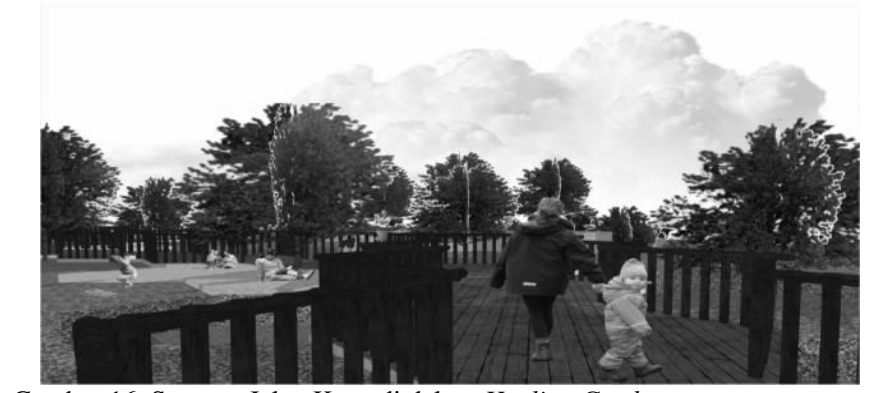

Gambar 16. Suasana Jalan Kayu di dalam Healing Garden

Sumber: Dokumentasi Pribadi

Konsep healing environment yang merupakan salah satu konsep pembentukkan lingkungan perawatan yang memadukan aspek fisik dan psikologis pasien di dalamnya yang bertujuan untuk mempercepat proses peyembuhan pasien. Prinsip-prinsip penerapan konsep tersebut sebagai

1) Desainnya harus mampu mendukung proses pemulihan baik fisik maupun psikis seseorang

2) Akses ke lingkungan luar

3) Adanya kegiatan-kegiatan lingkungan luar yang berhubungan langsung dengan alam

4) Desain diarahkan pada perwujudan kualitas ruang agar untuk mencapai hasil maksimal dalam proses pemulihan psikis pasien [4].

\section{B. Konsep bentuk: Heksagonal}

Konsep bentuk memilih bentuk heksagonal (segi enam) karena bentuk ini memiliki beberapa keunggulan disamping memiliki kelemahan pula. Keunggulan yang ada pada bentuk heksagonal adalah sebagai berikut:

1) Lebih kuat dan kokoh apabila disusun secara berkelompok, antar sisi heksagonal saling bersinggungan (salah satu bentuk yang tahan terhadap goncangan)

2) Bentuknya yang unik dan tatanan massa yang mudah disusun dan digubah

3) Lebih hemat dalam bahan pembuatan, dapat dihasilkan luasan ruangan semaksimal mungkin dengan bahan pembuatan seminimal mungkin.

Selain memiliki beberapa keunggulan, bentuk heksagonal juga memiliki beberapa kelemahan yaitu:

- Ruang dalam yang terbentuk memiliki sudut-sudut tajam sehingga banyak ruangan yang tidak efektif

- Penataan denah ruang dalam lebih sulit sehingga berdampak pula dengan tingkat kesulitan dalam penataan perabot-perabot.

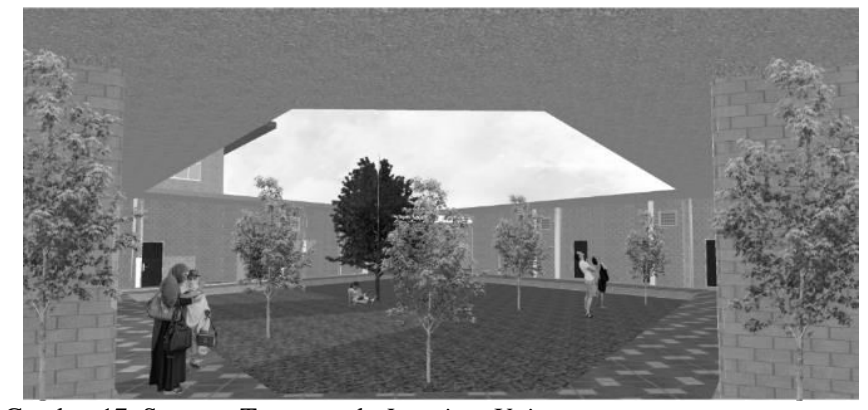

Gambar 17. Suasana Taman pada Inpatient Unit

Sumber: Dokumentasi Pribadi

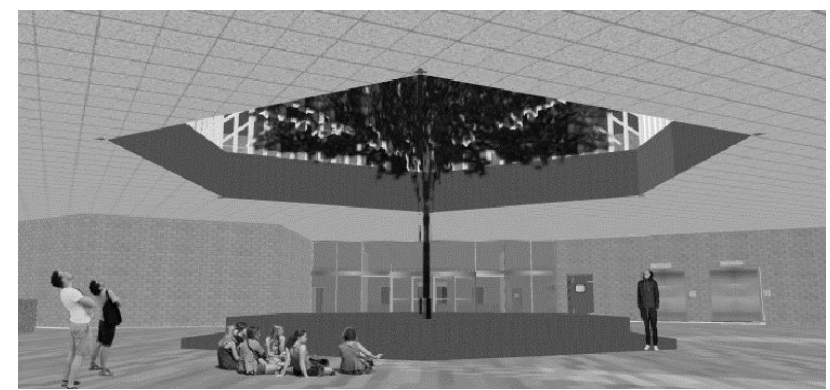

Gambar 18. Suasana Indoor

Sumber: Dokumentasi Pribadi

\section{Konsep Ruang}

Tuntutan Psikologis Ruang

Menurut Iggrid Gehl (dalam Rahmawati, 2010), secara psikologis, ruang dibagi menjadi 4 komponen meliputi skala, warna, tekstur dan garis [5].

\section{1) Skala Ruang}

Skala ruang menunjukkan perbandingan antara suatu elemen dengan elemen lain dalam ruang yang sama, acuannya menyesuaikan dengan ukuran tubuh manusia pengguna ruang tersebut. Secara psikologis, kesan yang timbul dari skala ruang yang umum yaitu perbandingan jarak antar dinding dengan tinggi ruang adalah:

- $\mathrm{D} / \mathrm{H}<1$ ruang yang terbentuk terlalu sempit, kesan tertekan

- $\mathrm{D} / \mathrm{H}=1$ ruang terasa seimbang

- $\mathrm{D} / \mathrm{H}>1$ ruang terasa agak besar

- $\mathrm{D} / \mathrm{H}>4$ pengaruh ruang tidak terasa

$\Rightarrow$ Penerapan skala ruang:

- Skala $\mathrm{D} / \mathrm{H}=1$

Ruang terapi medis, psikologis, dan terapi psikis, serta ruang-ruang lainnya

- $\quad$ Skala D/H > 1

Ruang hunian pasien agar pasien terasa relaks dan tidak tertekan. Ruang lobby karena bersifat semi public yang menampung banyak orang

- Skala D/H > 4

Healing garden karena taman ini bersifat publik 2) Warna sehingga didesain dengan sangat terbuka

Ditinjau dari efeknya terhadap kejiwaan dan sifat khas yang dimilikinya, warna dipilah dalam 2 kategori yaitu golongan warna panas dan golongan warna dingin. Warna-warna yang dekat dengan jingga atau merah digolongkan kepada warna panas atau hangat dan warna-warna yang berdekatan dengan warna biru kehijauan termasuk golongan warna dingin atau sejuk 


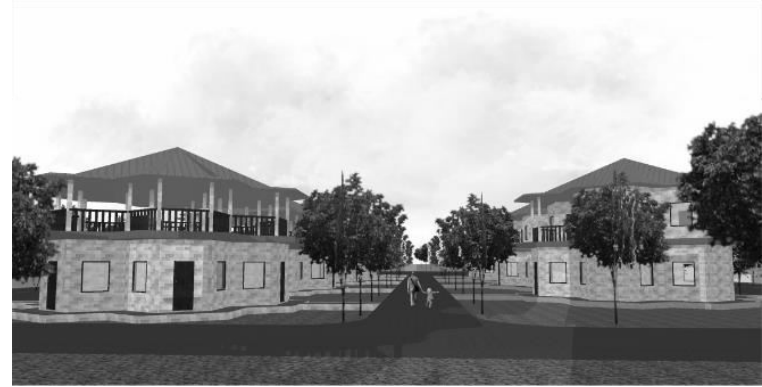

Gambar 19. Suasana Residence Unit

Sumber: Dokumentasi Pribadi.

Efek psikologis golongan warna panas, seperti merah, jingga, dan kuning memberi pengaruh psikologis panas, menggembirakan, menggairahkan dan merangsang. Golongan warna dingin hijau dan biru memberi pengaruh psikologis menenangkan, damai, sedangkan warna ungu membawa pengaruh menyedihkan. Untuk warna putih memberi pengaruh bersih, terbuka dan terang, warna hitam memberi pengaruh berat, formal, dan tidak menyenangkan (Pile, 1995 dan Birren, 1961). Warna dalam desain interior memiliki pengaruh yang kuat pada perasaan dan emosi penggunanya. Dan tidak menutup kemungkinan bahwa keadaan fisik penggunapun dapat dipengaruhi oleh warna-warna tertentu yang terdapat pada ruang yang ditempatinya.

$\Rightarrow$ Penerapan Warna:

Pada ruang perawatan medis, ruang terapi, ruang hunian menggunakan warna biru yang memberikan kesan tenang, damai dan bersih. Sedangkan pada ruang public seperti healing garden dan cafeteria menggunakan warna yang hangat seperti kuning, merah, dan warna-warna yang bersifat cerah.

\section{3) Tekstur}

Tekstur dapat membangkitkan perasaan lewat pandangan dan sentuhan. Tekstur juga dapat mengubah penampilan bentuk. Hal-hal yang membentuk tekstur antara lain corak, bentuk permukaan dan warna. Tetapi pengaruh tekstur ini dipengaruhi juga oleh jarak pandang, karena pada jarak pandang tertentu tekstur sudah tidak dapat berperan. Menurut bentuknya tekstur dibedakan atas:

- Tektur halus, ekspresinya menyenangkan dan tidak mempengaruhi dominasi objek penelitian atau ruang.

- Tekstur kasar, ekspresinya keras dan mendominasi penampilan bentuk.

$\Rightarrow$ Penerapan Tekstur:

$\Rightarrow$ Pada ruang terapi terbuka (healing garden), banyak diterapkan unsur-unsur seperti batu kerikil dan rumput yang berfungsi sebagai relaksasi bagi para pasien PTSD. Selain itu pada ruang-ruang terbuka yang bersifat publik penerapan elemen-elemen ekpos batu bata dan batu alam diharapkan dapat menghadirkan pengalaman ruang yang dapat membangkitkan ketenangan sekaligus semangat untuk sembuh.

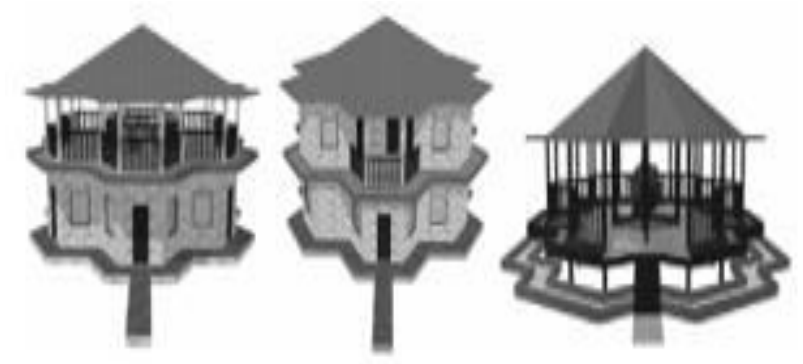

Gambar 20. Residence Tipe A dan B. Gazebo Sumber: Dokumentasi Pribadi.

\section{4) Garis}

Garis digunakan untuk mengekspresikan simbol-simbol tertentu yang terbentuk oleh garis itu sendiri sesuai dengan sugesti yang timbul.

- Vertikal, sugesti stabil, kuat, agung dan berwibawa.

- Horisontal, sugesti ketenangan, statis, hal yang tidak bergerak.

- Diagonal, sugesti ketidakstabilan, sesuatu yang bergerak.

- Lengkung, memberi sugesti dinamis, kuat dan megah.

$\Rightarrow$ Penerapan Garis:

Garis yang dipilih adalah dominan garis lengkung pada area aktifitas pasien PTSD karena mempertimbangkan kondisi dan keselamatan pasien trauma PTSD. Namun untuk area utilitas menggunakan garis vertical dan horizontal.

\section{KESIMPULAN}

Penyelesaian dari masalah Post Traumatic Stress Disorder (PTSD) atau stres pascatrauma pada korban bencana lumpur Sidoarjo dalam jurnal ini adalah berupa Pusat Kesehatan Mental dengan menggunakan pendekatan arsitektur perilaku (architecture behaviour). Pendekatan ini mempertimbangkan segala aspek yang menekankan pada perlunya memahami perilaku dan kebutuhan masyarakat di daerah terdampak bencana lumpur Sidoarjo dalam memanfaatkan suatu ruang untuk memulihkan kesehatan terutama kesehatan psikis. Sedangkan konsep yang diangkat adalah konsep Healing Environment (HE) yang diterapkan pada desain asritektur baik pada bagian luar (tata ruang luar) juga bagian dalam (tata ruang dalam) bangunan, sehingga dapat mempercepat waktu pemulihan kesehatan psikis para korban bencana lumpur Sidoarjo.

\section{DAFTAR PUSTAKA}

[1] Laurens and J. Marcella, Arsitektur dan Perilaku Manusia. Jakarta: Grasindo, 2004.

[2] S. Brand, How Buildings Learn: What Happens After They're Built. Penguin, 1995.

[3] J. Robert L Neary, "New Mental Health Design Guide,” 2010.

[4] F. Kurniawati, "Peran Healing Environment Terhadap Proses Penyembuhan," Universitas Gadjah Mada, 2007.

[5] N. Rahmawati, "Pusat Terapi Dan Rehabilitasibagi Ketergantungan Narkobad dengan Pendekatan Arsitektur Perilaku," UNS Surakarta, 2010 